\title{
Clinical management of esophagogastroduodenoscopy by clinicians under the former guidelines of the Japan Gastroenterological Endoscopy Society for patients taking anticoagulant and antiplatelet medications
}

\author{
Kunio Iwatsuka $\cdot$ Takuji Gotoda $\cdot$ Chika Kusano $\cdot$ \\ Masakatsu Fukuzawa - Katsutoshi Sugimoto • \\ Takao Itoi · Takashi Kawai · Fuminori Moriyasu \\ Received: 11 September 2013/Accepted: 16 December 2013/Published online: 8 January 2014 \\ (c) The International Gastric Cancer Association and The Japanese Gastric Cancer Association 2014
}

\begin{abstract}
Background The 2005 Japan Gastroenterological Endoscopy Society (JGES) guidelines for the management of antithrombotic drugs focused on the increasing risks of bleeding, even from biopsy during scheduled esophagogastroduodenoscopy (EGD). The new 2012 guidelines emphasized the prevention of thromboembolic complications. To compare with the new guidelines, we investigated the clinical management of EGD by clinicians under the former JGES guidelines for patients taking antithrombotic agents.

Methods Medical records of 4574 patients (mean age 63.4 years, range 3-96 years, male/female ratio 2805/1769) who underwent scheduled EGD from April 2011 to March 2012 were reviewed retrospectively. The prescribed agents, pre-existing comorbidities, drug cessation before EGD, bleeding, and thromboembolic complications were investigated.

Results Five hundred forty-six patients $(12.0 \%)$ were taking antithrombotic drugs (aspirin, 313; warfarin, 134; cilostazol, 57; clopidogrel, 59; ethylicosapentate, 40; prostaglandin preparations, 41; ticlopidine, 29; icosapentate, 24; dipyridamole, 4); 116 and 29 patients, respectively, were managed with a combination of 2 or 3 agents. Among 490 patients whose medical records were precisely documented, $40.6 \%$ underwent EGD without cessation.
\end{abstract}

\footnotetext{
K. Iwatsuka - T. Gotoda $(\bowtie) \cdot$ C. Kusano - M. Fukuzawa ·

K. Sugimoto $\cdot$ T. Itoi $\cdot$ F. Moriyasu

Department of Gastroenterology and Hepatology,

Tokyo Medical University, 6-7-1 Nishishinjuku,

Shinjuku-ku, Tokyo 160-0023, Japan

e-mail: takujigotoda@yahoo.co.jp

T. Kawai

Endoscopy Center, Tokyo Medical University, Tokyo, Japan
}

Bleeding and thromboembolic complications were not observed. The most common pre-existing comorbidity was ischemic heart disease $(27.9 \%)$, followed by carotid or intracranial large artery atherosclerosis $(20.5 \%)$, cerebral infarction or transient ischemic attack $(20.3 \%)$, and atrial fibrillation $(15.9 \%)$. Patients with pre-existing comorbidity requiring anticoagulants frequently underwent EGD without cessation.

Conclusion We revealed the low impact of the 2005 JGES guidelines on the management of antithrombotic drugs. Our physicians have reasonably decided to continue antithrombotic drugs before EGD according to the risk of thromboembolism.

Keywords Antithrombotic drug - Anticoagulant drug . Antiplatelet drug · Drug cessation .

Esophagogastroduodenoscopy

\section{Introduction}

Over the past decade, there has been a widespread prophylactic use of antithrombotic drugs for cardiovascular, cerebrovascular, and venous thromboembolic diseases [1]. There is solid evidence supporting the prophylactic use of antithrombotic agents for cerebrovascular and cardiovascular events [2, 3]. However, they may also increase the risk of bleeding in the gastrointestinal tract, particularly for patients receiving combined antithrombotic therapy [4-8].

Many endoscopists have had more opportunities to perform diagnostic and therapeutic endoscopy on patients receiving antithrombotic drugs. From the standpoint of endoscopists, these drugs should be stopped to reduce the risk of hemorrhage. On the other hand, cessation of antithrombotic drugs exposes the patient to the risk of 
thromboembolism due to each underlying condition. Discontinuation of these agents during the periendoscopic period can induce thromboembolic complications. When these occur, the mortality rate from embolism is higher than that from bleeding [9]. Therefore, the dilemma between the risks of thromboembolic events and gastrointestinal bleeding, and the difficulty in estimating thromboembolic risk for each patient's comorbidity, have been major concerns for endoscopists.

In 2005, the Japan Gastroenterological Endoscopy Society (JGES) established guidelines on the management of anticoagulants and antiplatelet agents for endoscopic procedures [10]. The feature of these guidelines is that the risk of procedure-related bleeding is more heavily weighted than the risk of a thromboembolism caused by ceasing these medications, based on the solitary study [11]. In these guidelines, cessation is recommended even for scheduled esophagogastroduodenoscopy (EGD) including biopsy, although cessation is not indicated as necessary in most western guidelines [12-16]. This difference was based on racial differences in bleeding risk between Asians and Caucasians as mentioned in the 2005 JGES guidelines [10].

There is no solid evidence, however, to support higher bleeding risk in Asians; several studies reported that no complications related to bleeding were observed in Japanese patients who underwent endoscopic biopsy without cessation of antithrombotic drugs [9, 17-19].

Because solid evidence on the management of antithrombotic drugs for EGD is absent, the impact of these 2005 guidelines is generally low in most institutions in Japan [17-19].

\section{JGES guidelines}

JGES established new guidelines on the management of anticoagulants and antiplatelet agents for endoscopic procedures in 2012 [20]. According to these guidelines, as with western guidelines, avoiding thromboembolic complications is weighted more than avoiding bleeding. It is not necessary to withdraw antithrombotic drugs before a scheduled EGD, and even before a minimally invasive procedure such as biopsy, in cases of prescribing a single agent. Additionally, in these guidelines, as opposed to the former guidelines, high-risk thromboembolic comorbidities for cessation are listed in detail. The cessation periods before EGD of antithrombotic drugs indicated in the 2005 and 2012 JGES guidelines are shown in Table 1.

The purpose of this study was to investigate the reasonable management of EGD for patients taking antithrombotic drugs, which is unclear under the former JGES guidelines. We retrospectively investigated the prescribed agents, complications, pre-existing comorbidities, and the cessation rates of each antithrombotic drug in a singlecenter setting. Furthermore, referring to the 2012 guidelines, we clarified the proportion of patients with high-risk thromboembolic comorbidity and the cessation rates of the prescribed agents.

\section{Method}

We retrospectively investigated patients who underwent scheduled EGD from April 1, 2011 to March 31, 2012 using medical records of the Department of Gastroenterology at Tokyo Medical University under the 2005 JGES guidelines. We do not have any original written criteria concerning the management of antithrombotic drugs and pre-existing comorbidities. Therefore, the cessation had been principally determined by the doctors who order EGD or who prescribe antithrombotic drugs as in many institutions in Japan [9]. However, they are not necessarily the performers of EGD. The doctors who perform EGD are from various departments and include physicians, surgeons, pediatricians, well-trained endoscopists, junior residents, and senior residents in our hospital.

Patients who underwent emergency EGD with apparent clinical symptoms were excluded, because the appropriate cessation period could not be secured before EGD on a case-by-case basis.

We defined the following as antiplatelet agents: cyclooxygenase inhibitors (e.g., aspirin), clopidogrel, phosphodiesterase inhibitors (e.g., cilostazol), purinergic receptor antagonists (e.g., ticlopidine), dipyridamole, and prostaglandin preparations, eicosapentaenoic acid preparations (e.g., icosapentate), serotonin receptor antagonists (e.g., sarpogrelate). Warfarin was classified as an anticoagulant.

Table 1 Management of antithrombotic agents for scheduled EGD in 2005 and 2012 JGES guidelines

\begin{tabular}{|c|c|c|c|c|c|}
\hline & Aspirin & Ticlopidine & $\begin{array}{l}\text { Combination therapy } \\
\text { with aspirin and } \\
\text { ticlopidine }\end{array}$ & $\begin{array}{l}\text { Other } \\
\text { antiplatelet } \\
\text { agents }\end{array}$ & Warfarin \\
\hline $\begin{array}{l}2005 \text { JGES } \\
\text { guidelines }\end{array}$ & $\begin{array}{l}\text { Withdraw } \\
3 \text { days }\end{array}$ & $\begin{array}{l}\text { Withdraw } \\
5 \text { days }\end{array}$ & $\begin{array}{l}\text { Withdraw both } \\
7 \text { days }\end{array}$ & $\begin{array}{l}\text { Withdraw } \\
5 \text { days }\end{array}$ & $\begin{array}{l}\text { Withdraw } 3-4 \text { days } \\
\text { (check INR }<1.5 \text { before procedures) }\end{array}$ \\
\hline $\begin{array}{l}2012 \text { JGES } \\
\text { guidelines }\end{array}$ & Continue & & & & Continue (check INR $<1.5$ before procedures) \\
\hline
\end{tabular}


Table 2 Pre-existing comorbidities referring to the 2012 JEGS guidelines

\begin{tabular}{|c|c|}
\hline Pre-existing comorbidities & High risk of thromboembolism \\
\hline \multicolumn{2}{|c|}{ Pre-existing comorbidity requiring antiplatelet drug } \\
\hline Ischemic heart disease & $\begin{array}{l}\text { Within } 2 \text { months after metallic } \\
\text { coronary stent placement } \\
\text { Within } 12 \text { months after coronary } \\
\text { drug-eluting coronary stent } \\
\text { placement }\end{array}$ \\
\hline $\begin{array}{l}\text { Atherothrombotic cerebral } \\
\text { infarction/transient ischemic } \\
\text { attack }\end{array}$ & $\begin{array}{l}\text { With intracranial large artery } \\
\text { stenosis (more than } 50 \% \text { ) }\end{array}$ \\
\hline Arteriosclerosis obliterans & $\begin{array}{l}\text { Arteriosclerosis obliterans } \\
\quad \text { (fontaine classification 3-4) }\end{array}$ \\
\hline $\begin{array}{l}\text { Carotid/intracranial large artery } \\
\text { atherosclerosis }\end{array}$ & $\begin{array}{l}\text { Within } 2 \text { months of cerebral } \\
\text { revascularization (carotid } \\
\text { endarterectomy, carotid artery } \\
\text { stenting) } \\
\text { High risk of cerebral infarction } \\
\text { condition (evaluated by carotid } \\
\text { ultrasound image or magnetic } \\
\text { resonance and head and neck } \\
\text { blood vessel image) }\end{array}$ \\
\hline \multicolumn{2}{|c|}{ Pre-existing comorbidity requiring anticoagulants } \\
\hline \multicolumn{2}{|c|}{ After cardiogenic cerebral embolism } \\
\hline \multicolumn{2}{|l|}{ Atrial fibrillation } \\
\hline \multicolumn{2}{|c|}{ Status post heart valve replacement } \\
\hline \multicolumn{2}{|c|}{ Deep venous thrombosis/pulmonary embolism } \\
\hline Anti-phospholipid antibody syı & drome \\
\hline
\end{tabular}

We investigated the following pre-existing comorbidities: ischemic heart disease, cerebral infarction (CI) and transient ischemic attack (TIA), arteriosclerosis obliterans, carotid and intracranial large artery atherosclerosis, cardiogenic cerebral embolism, atrial fibrillation, status post heart valve replacement, deep venous thrombosis (DVT) and pulmonary embolism (PE), and anti-phospholipid antibody syndrome. We also researched the antithrombotic cessation rates in patients with these pre-existing comorbidities.

Additionally, referring to the 2012 JEGS guidelines, we clarified the proportion of high-risk patients with preexisting comorbidities (Table 2). We described all patients who were prescribed warfarin as being in a high-risk condition of thromboembolism regardless of their comorbidities, for the reason that mortality is high when embolic complications occur. Statistical analyses were conducted using the $\chi^{2}$ test. A $P$ value of $<0.05$ was considered to indicate a statistically significant difference.

\section{Results}

Among 4574 patients (mean age 63.4 years, range 3-96 years, male/female 2805/1769), 546 patients $(12.0 \%$ ) were prescribed antithrombotic drugs. A total of 199 patients underwent EGD without cessation, and 56 patients were excluded because their medical records did not document the decision whether to withdraw antithrombotic drugs.

A total of 291 patients (59.4\%) underwent EGD after an antithrombotic cessation period as recommended by the 2005 JGES guidelines, 139 out of 291 (47.8\%) patients underwent a biopsy after the cessation period, and 13 out of $199(6.5 \%)$ patients underwent a biopsy without cessation (Table 3).

We made histograms for patients taking each agent (aspirin, clopidogrel, cilostazol, ticlopidine, dipyridamole, prostaglandin preparations, icosapentate, sarpogrelate, and warfarin), a single agent, 2 agents, and 3 agents (Fig. 1). The most common antithrombotic drug was aspirin $(57.3 \%)$, followed by warfarin $(24.5 \%)$, clopidogrel $(10.8 \%)$, cilostazol $(10.4 \%)$, prostaglandin preparations $(7.5 \%)$, icosapentate $(7.3 \%)$, sarpogrelate $(4.4 \%)$, ticlopidine $(5.3 \%)$, and dipyridamole $(0.7 \%)$.

Figure 2 shows the cessation rates of patients with preexisting comorbidities out of 490 patients for whom the decision as to whether to withdraw antithrombotic drugs was documented. The most common pre-existing comorbidity requiring antithrombotic drugs was ischemic heart disease in 195 patients $(27.9 \%)$, followed by arteriosclerosis obliterans (9.0\%), CI/TIA (20.3\%), carotid/intracranial large artery atherosclerosis $(20.5 \%)$, cardiogenic cerebral embolism (2.9\%), atrial fibrillation (15.9\%), status post heart valve replacement $(2.2 \%)$, and DVT/PE $(3.7 \%)$.

The number of patients with thromboembolic high-risk comorbidities was $178(32.6 \%)$ out of 546 patients.

Table 3 Characteristics of patients

\begin{tabular}{lllll}
\hline & $\begin{array}{l}\text { Total number } \\
\text { of patients }\end{array}$ & $\begin{array}{l}\text { Number of patients taking } \\
\text { antithrombotic drugs }\end{array}$ & $\begin{array}{l}\text { With } \\
\text { cessation }\end{array}$ & $\begin{array}{l}\text { Without } \\
\text { cessation }\end{array}$ \\
\hline Number of patients & 4574 & $546(12.0 \%)$ & $291(59.4 \%)$ & $199(40.6 \%)$ \\
Mean age (years) & $63.4(3-96)$ & $71.0(25-91)$ & $71.0(27-88)$ & $71.2(25-91)$ \\
Sex (M:F) & $2805: 1769$ & $401: 145$ & $213: 78$ & $149: 50$ \\
Biopsy & $910(19.9 \%)$ & $169(31.0 \%)$ & $139(47.8 \%)$ & $13(6.5 \%)$ \\
\hline
\end{tabular}




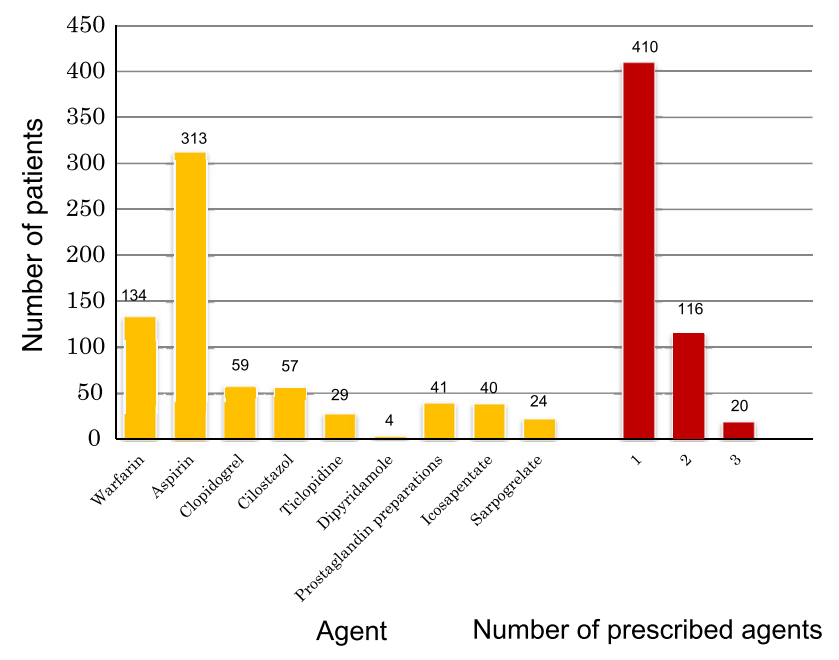

Fig. 1 Number of patients taking each agent (warfarin, aspirin, clopidogrel, cilostazol, ticlopidine, dipyridamole, prostaglandin preparations, icosapentate, sarpogrelate), and number taking a single agent, a combination of 2 agents, and 3 agents (total of 546 patients)

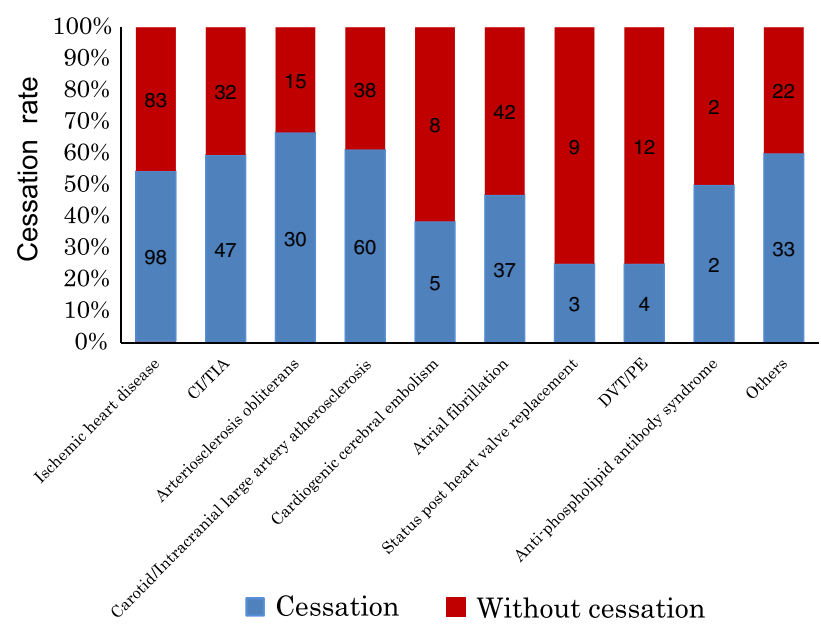

Fig. 2 Cessation rates of patients with pre-existing comorbidities for whom the decision as to whether to withdraw antithrombotic drugs was documented (total of 490 patients)

With cessation $(N=291) \quad$ Without cessation $(N=199)$

- High risk of thromboembolism

- High risk of thromboembolism
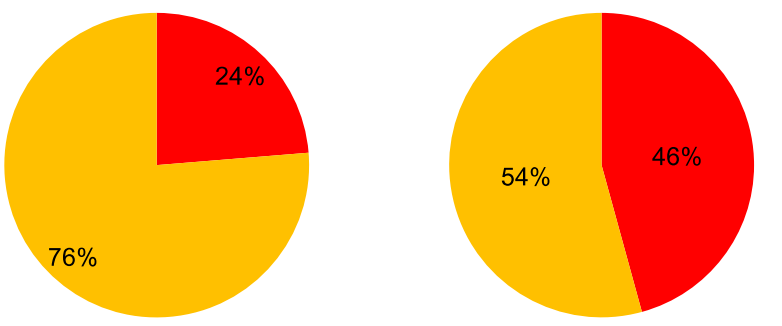

$P<0.0001$

Fig. 3 The proportion of thromboembolic high-risk patients with comorbidities with or without cessation (total of 490 patients)
Figure 3 shows the proportion of thromboembolic highrisk patients with comorbidities with or without cessation among 490 patients whose medical records of the decision whether to withdraw antithrombotic drugs were documented. Among these 490 patients, 160 patients were thromboembolic high-risk patients; 91 (56.9\%) out of these 160 patients underwent EGD without cessation. There was a tendency for patients with high-risk thromboembolism comorbidities to undergo EGD without cessation $(P<0.0001)$.

\section{Complications}

In this study, no symptoms related to thromboembolic events or gastrointestinal bleeding were observed. No patient underwent invasive procedures without antithrombotic cessation.

\section{Discussion}

We clarified the present daily clinical practice regarding the management of EGD with antithrombotic drugs under the former JGES guidelines. The results showed the low impact of the 2005 guidelines on the management of antithrombotic drugs for EGD, in line with reports from several institutions [9, 17-19]. These results indicated a large discrepancy between daily clinical practice and the recommendations of the former JGES guidelines.

These results indicated the polarization of the respective cessation rates of each antithrombotic drug. There was a tendency for patients taking warfarin or a combination of 2 or 3 agents to frequently undergo EGD without cessation (warfarin, $P<0.0001$; combination of 2 drugs, $P<0.0001$; combination of 3 drugs, $P<0.0001)$. In contrast, most patients taking a single agent or prostaglandin preparations underwent EGD with cessation $(P<0.0001$ and $P<0.05$, respectively); these patients may be considered to be at low risk for a lethal thromboembolic event.

Prostaglandin preparations are generally prescribed for arteriosclerosis obliterans or lumbar spinal canal stenosis; therefore, cessation may be regarded as safe. Also, the proportion of patients prescribed prostaglandin preparations who had high-risk thromboembolic comorbidity (Fontaine classification 3-4) was only $7.3 \%$ (3/41).

Patients with DVT or PE, status post heart valve replacement, or atrial fibrillation frequently underwent EGD without cessation (DVT/PE, $P<0.001$; status post heart valve replacement, $P<0.05$; atrial fibrillation, $P<0.05$, and most of them had been prescribed warfarin.

The proportion of patients with comorbidities requiring antiplatelet drugs was not significantly different between those with or without cessation. We retrospectively 
investigated the medical history from medical records, but could not obtain detailed diagnostic methods, such as coronary angiography and brain MRI, in a number of patients. Their pre-existing comorbidities were possibly diagnosed only by symptoms without detailed examination. Aged patients with ischemic heart disease, CI, and arteriosclerosis obliterans were often prescribed agents without detailed examination. Most of them were possibly prescribed antiplatelet drugs primarily as prophylaxis, thus we assumed that cessation was regarded as safe for them.

This study revealed the reasonable management of each pre-existing comorbidity in their current clinical status. Until recently, it has been difficult to estimate the thromboembolic risk of various kinds of pre-existing comorbidities; therefore, decisions regarding cessation were mainly left to prescribing physicians in non-gastroenterological specialties such as cardiology, neurology, and orthopedics. Most of these prescribing physicians may have been unfamiliar with the JGES guidelines; this may partly explain the low impact of the former JGES guidelines.

Another possible reason for the low permeation of the 2005 JGES guidelines might be the publishing of the 2009 ASGE guidelines [16], but there were no similar clinical studies concerning the management of antithrombotic agents for EGD before the 2009 ASGE guidelines were published that can be compared with our study. Only 1 study about the management of antithrombotic agents for endoscopy before the 2009 ASGE guidelines were published was reported by Ono et al. [17], but the participating patients included not only patients who underwent scheduled EGD, but also patients who underwent colonoscopy, EUS, and invasive procedures (EMR, ESD). They retrospectively investigated 8921 patients who underwent endoscopy in 2008 at a single university hospital. They reported that patients taking warfarin alone (126/244, $51.6 \%)$, aspirin alone $(211 / 640,33.0 \%)$, ticlopidine alone $(8 / 32,25.0 \%)$, or a combination of aspirin and ticlopidine $(65 / 95,68.4 \%)$ underwent endoscopy without cessation. In our study patients taking warfarin alone (48/ $79,60.8 \%)$, aspirin alone $(59 / 178,33.1 \%)$, ticlopidine alone $(4 / 13,30.8 \%)$, or a combination of aspirin and ticlopidine $(4 / 11,36.4 \%)$ underwent EGD without cessation. These differences in withdrawal rates are not statistically significant, although participating patients in each study were somewhat different. We assert that the reason for the low permeation of the 2005 JGES guidelines was not the publishing of the 2009 ASGE guidelines, even though the 2009 ASGE guidelines were more reasonable for prescribing doctors in daily clinical practice than the 2005 JGES guidelines. Additionally we assume that the 2012 JGES guidelines are more suitable for daily clinical practice because they are based on the 2009 ASGE guidelines.
The 2012 JGES guidelines are based on the Delphi technique, which is an interactive forecasting method that relies on a panel of experts. Its evidence level may be insufficient. As opposed to the former JGES guidelines, "high-risk thromboembolic comorbidities for cessation" are listed in detail in the 2012 JGES guidelines. Referring to this information, we investigated the management of the prescribed antithrombotic drugs. These high-risk patients frequently underwent EGD without cessation, thus the 2012 JGES guidelines may be useful in daily clinical practice.

The limitations of this study include its small number of patients and its retrospective design over the period of only 1 year. Our research was conducted 6 years after the JGES guidelines were published; therefore, the change over time of the management of antithrombotic drugs is unclear. Additionally, there can be a selection bias because this study was conducted in only a single institution. Further investigation with a multicenter design is required.

To date, the situation surrounding the management of anticoagulants and antiplatelet agents for endoscopy in Japan has been confusing. At this point, it is necessary to follow the new guidelines and accumulate data to provide solid evidence.

Conflict of interest The authors have no conflicts of interest to disclose.

\section{References}

1. Makar GA, Ginsberg GG. Therapy insight: approaching endoscopy in anticoagulated patients. Nat Clin Pract Gastroenterol Hepatol. 2006;3:43-52.

2. Diener HC, Cunha L, Forbes C, Sivenius J, Smets P, Lowenthal A. European stroke prevention study. 2. Dipyridamole and acetylsalicylic acid in the secondary prevention of stroke. J Neurol Sci. 1996;143:1-13.

3. Yusuf S, Zhao F, Mehta SR, Chrolavicius S, Tognoni G, Fox KK. Effects of clopidogrel in addition to aspirin in patients with acute coronary syndromes without ST-segment elevation. N Engl J Med. 2001;345:494-502.

4. Weil J, Colin-Jones D, Langman M, Lawson D, Logan R, Murphy $\mathrm{M}$, et al. Prophylactic aspirin and risk of peptic ulcer bleeding. BMJ. 1995;310:827-30.

5. Sorensen HT, Mellemkjaer L, Blot WJ, Nielsen GL, Steffensen FH, McLaughlin JK, et al. Risk of upper gastrointestinal bleeding associated with use of low-dose aspirin. Am J Gastroenterol. 2000;95:2218-24.

6. Hallas J, Dall M, Andries A, Andersen BS, Aalykke C, Hansen $\mathrm{JM}$, et al. Use of single and combined antithrombotic therapy and risk of serious upper gastrointestinal bleeding: population based case-control study. BMJ. 2006;333:726.

7. Taha AS, Angerson WJ, Knill-Jones RP, Blatchford O. Upper gastrointestinal mucosal abnormalities and blood loss complicating low-dose aspirin and antithrombotic therapy. Aliment Pharmacol Ther. 2006;23:489-95. 
8. Aronow HD, Steinhubl SR, Brennan DM, Berger PB, Topol EJ. Bleeding risk associated with 1 year of dual antiplatelet therapy after percutaneous coronary intervention: insights from the clopidogrel for the reduction of events during observation (CREDO) trial. Am Heart J. 2009;157:369-74.

9. Fujishiro M, Oda I, Yamamoto Y, Akiyama J, Ishii N, Kakushima $\mathrm{N}$, et al. Multi-center survey regarding the management of anticoagulation and antiplatelet therapy for endoscopic procedures in Japan. J Gastroenterol Hepatol. 2009;24:214-8.

10. Ogoshi K, Kaneko E, Tada M, Mine T, Yoshino J, Yahagi N, et al. The management of anticoagulation and antiplatelet therapy for endoscopic procedures. Gastroenterol Endosc. 2005;47: 2691-5 [in Japanese].

11. Komatsu T, Tamai Y, Takami H, Yamagata K, Fukuda S, Munakata A. A study for determination of the optimal cessation period of therapy with anti-platelet agents prior to invasive endoscopic procedures. J Gastroenterol. 2005;40:698-707.

12. Lee SY, Tang SJ, Rockey DC, Weinstein D, Lara L, Sreenarasimhaiah $\mathrm{J}$, et al. Managing anticoagulation and antiplatelet medications in GI endoscopy: a survey comparing the east and the west. Gastrointest Endosc. 2008;67:1076-81.

13. Zuckerman MJ, Hirota WK, Adler DG, Davila RE, Jacobson BC, Leighton JA, et al. ASGE guideline: the management of lowmolecular-weight heparin and nonaspirin antiplatelet agents for endoscopic procedures. Gastrointest Endosc. 2005;61:189-94.
14. Napoleon B, Boneu B, Maillard L, Samama CM, Schved JF, Gay $\mathrm{G}$, et al. Guidelines of the french society for digestive endoscopy (SFED). Endoscopy. 2006;38:632-8.

15. Veitch AM, Baglin TP, Gershlick AH, Harnden SM, Tighe R, Cairns S. Guidelines for the management of anticoagulant and antiplatelet therapy in patients undergoing endoscopic procedures. Gut. 2008;57:1322-9.

16. Anderson MA, Ben-Menachem T, Gan SI, Appalaneni V, Baneriee S, Cash BD, et al. Management of antithrombotic agents for endoscopic procedures. Gastrointest Endosc. 2009;70:1060-70.

17. Ono S, Fujishiro M, Hirano K, Niimi K, Goto O, Kodashima S, et al. Retrospective analysis on the management of anticoagulants and antiplatelet agents for scheduled endoscopy. J Gastroenterol. 2009;44:1185-9.

18. Ono S, Fujishiro M, Shinya K, Yu T, Chihiro M, Rie M-M, et al. Evaluation of safety of endoscopic biopsy without cessation of antithrombotic agents in Japan. J Gastroenterol. 2012;47:770-4.

19. Ono S, Fujishiro M, Kodashima S, Minatsuki C, Hirano K, Niimi $\mathrm{K}$, et al. Controversy on the management of anticoagulants and antiplatelet agents for scheduled endoscopy. Dig Endosc. 2011;23:1-4.

20. Fujimoto K, Fujishiro M, Katou M, Higuchi K, Iwakiri R, Sakamoto $\mathrm{C}$, et al. The management of anticoagulation and antiplatelet therapy for endoscopic procedures. Gastroenterol Endosc. 2012;54:2075-102 [in Japanese]. 